\title{
Death from Marathon Race Following Acute Myocardiac Infarction with Ruptured Berry Aneurysm
}

\author{
Martin Nnoli ${ }^{1}$,Godwin Ebughe ${ }^{1}$, Omotoso,Ayodele Joshua, ${ }^{1}$ \\ Theophilus Ipeh Ugbem ${ }^{2}$ \\ University of Calabar, Dept of Anatomic \& Forensic Medicine, Calabar, Cross-River State. ${ }^{1,2}$
}

\begin{abstract}
Strenuous physical activity like marathon race put a lot of strain on the heart with its attendant physical and psychological view point. This individual often dies suddenly as most of them are with sub-clinical to over heart diseases and; at times with brain lesion like ruptured aneurysm. ${ }^{l}$

Ruptured aneurysm is the most frequent extracardiac cause for sudden death arising in the cardiovascular system. These always arises on the cerebral vessels as a result of artheroma formation on the vessels which obstructs free flow of the blood with its extensive narrowing of the blood vessels plus attributed to consequences.

This type of aneurysm often resides at the circles of willis at the bifurcation and links together. ${ }^{2}$ Most are giant type and are in form of fusiform/dissection type occurs in traumatic dissection or congenital ateriopathy and arteriosclerosis. ${ }^{3-6}$ However, organic diseases like hypertension and few other conditions like smoking, gender males at younger to middle aged adults are more prone to aneurismal deaths. ${ }^{7,8}$

The case is a young man of 32 years who is on $32 \mathrm{~km}$ marathon race as part of fitness criteria for promotion who suddenly slumped and was brought in the hospital; though certified dead already (brought in dead).
\end{abstract}

Keyword: Race, Male, Hypertension, Death. There is no conflict of interest among the authors.

Accepted Date: 01 July 2013

\section{Introduction}

A lot of factors could cause sudden death in a young to middle aged adult. However, unawareness uncontrollable cardiovascular disease with its attendant strenuous exercises (marathon race) could lead to sudden death. A few of cases may not be known as individual progresses from acute infarction to sub-acute with softening of the wall of the heart, potential for rupture occurs as the individual collapses and dies as in our case. ${ }^{9}$ There is no conflict of interest.

\section{Case Report}

A 32years old male, who by nature of his duty must be fit at all time due for promotion was placed on $32 \mathrm{KM}$ marathon race with others. In cause of the race he slumped and was rushed to a tertiary hospital where he was certified dead.

\section{Autopsy Findings}

Autopsy revealed an obese young male with left temporalis contusion injury and the grove of the nose laceration otherwise no any other physical findings. Systemic reviews shows:-

Heart: Heart is enlarged weighed $550 \mathrm{gms}$ and thickened left ventricular wall $2 \mathrm{~cm}$ (Normal upperlimit $1.5 \mathrm{~cm}$ ) and interventricular septum. There was atherosclerosis with narrowing of the 3 major coronary vessels lumen to $50 \%$. There is gross pale red of the serial sectioning of the myocardium with yellowish patches. There is left ventricular hypertrophy with pointal,bulbous chordea tindinea.

Brain: The brain showed mild to a moderate cerebral edema and mild subacute haemorrhages at left temporalis area. There is also rupture of the anterior communicating artery of the circle of willis with leakage blood to the brain substances.

Causes of death was said to be acute rupture of berry aneurysm with myocardiac infarction consequent to long standing hypertensive heart disease following strenuous exercise - marathon race. 
Limitation Of Study: We could not do any toxicology as to exclude any drugs, catecholamine's or any other things patient must have taken prior to the race like cannabis/hard drugs. These are known to affect the heart while enhancing performance of the person who took such substances.

Also there is no history of past medical history available to us as he was brought dead by his superior officer who knows nothing about that; plus the fact he just arrived to another state for the course (program).

\section{Results}

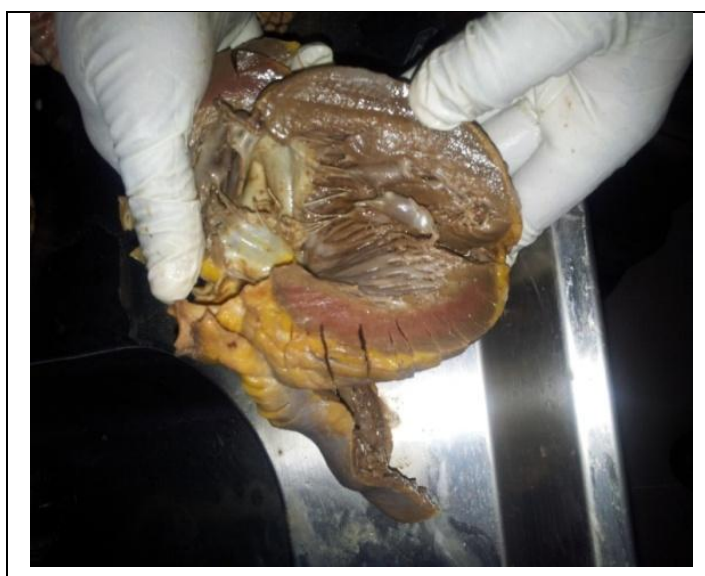

Figure 1

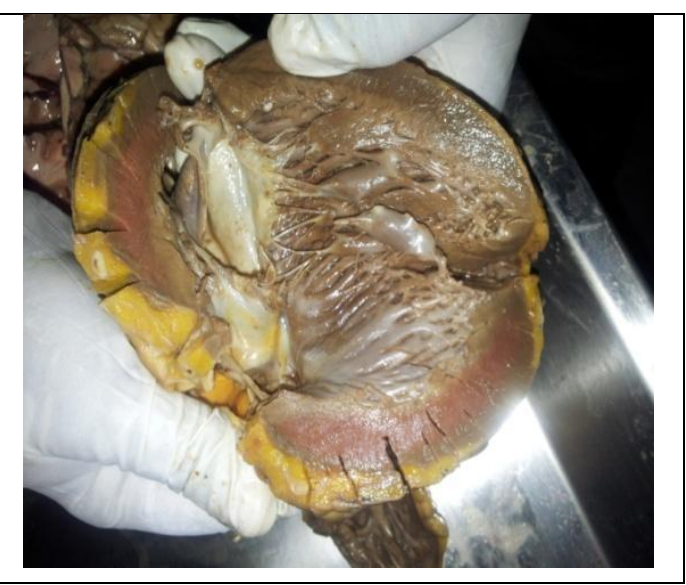

Figure 2

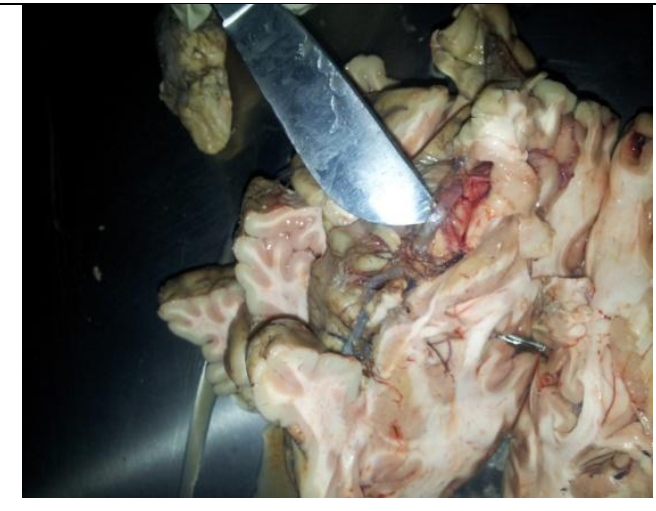

Figure 3

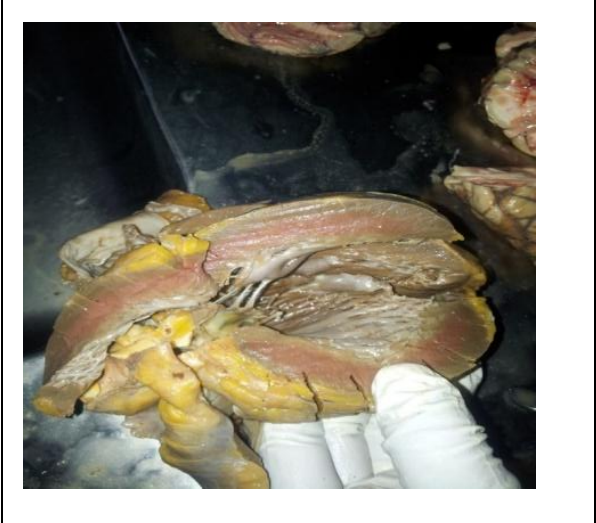

Figure 4

\section{Discussion}

The most common cause of deaths in young and middle aged arising from cardiovascular system is a sudden rupture of an aneurysm, almost always cerebra vessels. As with coronary disease, arterial spasm has been invoked as a cause of sudden death in ruptured berry aneurysm hence may death results after physical strenuous sporting activity as in our case.

Since our patient has hypertensive heart disease with left ventricular hypertrophy these could have exacerbated the relative coronary insufficiency. This is apart from the fact we appreciate the level of artheroma formation of the vessels which have led to the narrowing of the coronary lumen with its poor perfusion of blood supply to the myocardium. Also the weight of the heart above normal-550 gms is obviously a candidate for sudden death with or without coronary artery stenosis.

The figure 1 depicts left ventricular hypertrophy with thickened left ventricular wall $2 \mathrm{~cm}$ which is above the upper limit of $1.5 \mathrm{~cm}$; and pointal, bulbous chordea tindinea.

Figure 2 showed linear pale reddish zone on both cut surfaces of the heart with foci of scarring and fibrotic yellowish opaque mitral valve.

Figure 3 showed ruptured zone of the anterior communicating artery lifted with the knife to depict area of rupture which measures approximately $0.8 \mathrm{~cm}-1 \mathrm{~cm}$ tear leaking blood to the brain substances.

Figure 4 shows features of figures $1 \& 2$ with yellowish patches of the wall- possible healed scars of previous myocardiac infarction.

Mechanism of death though no infarct, seems to be due to electrical instability from chronic hypoxia as sudden stresses as exercise or emotion can suddenly cause arrhythmias. 


\section{References}

[1]. Knight's Forensic Pathology: The pathology of sudden death $3^{\text {rd }}$ edition chapter 25 page 509-11

[2]. International study of unruptured intracranial investigators. Unruptured intracranial aneurysms - risk of rupture and risks of surgical intervention. International study of unruptured intracranial aneurysm investigators. NEJM 1988; 339; 1725-1733

[3]. Pig Hw and Zierki J. Giant Cerebral Aneurysms. Neurosurg. Rev.1982;5: 117-48

[4]. Nakayama Y, Tanka A, Kumate S, Tomonaga M et al. Giant frusiform aneurysm of the basilar artery: Consideration of its Pathogenesis. Surg. Neurol 1999; 51: 140-145

[5]. Anson JA, Lawton MY and Spetzler RF.Characteristics and Surgical Treatment of dolicholectatic and fusiform aneurysms. J Neurosurg 1996; 84: 185-93

[6]. Drake C G and Peeless SJ. Giant frusiform intracranial aneurysm: Review of 120 patients treated surgically from 1965-1992. J. Neurology 1997; 87: 141-162

[7]. Stebbens WE. Etiology of intracranial lesion aneurisms. J. Neurosurg 1989; 70: 823-831

[8]. Connolly ES, Chondhri TF, et al. Influence of smoking, Hypertension and Sex on the phenotypic expression of familial intracranial aneurysms in siblings. Neurosurgery 2001; 48: 64-69.

[9]. Vincent Dimaio, Suzanna Dana. Handbook of Forensic Pathology, $2^{\text {nd }}$ Edition page 40. 